\title{
ANTONIO BUERO VALLEJO EN HUNGRÍA ${ }^{1}$
}

\author{
ANTONIO BUERO VALLEJO IN HUNGARY
}

\author{
Eszter KATONA \\ Universidad de Szeged \\ katonaeszter@gmail.com
}

\begin{abstract}
Resumen: El objetivo del presente artículo es ofrecer un análisis abarcador sobre la recepción en Hungría de la obra de Antonio Buero Vallejo. Mencionaremos las once traducciones y, después, examinaremos, a través de la crítica de la prensa, los cinco estrenos húngaros de sus tres dramas: En la ardiente oscuridad, puesto en escena dos veces (1962, 1976); El sueño de la razón, montado en 1974; y los dos estrenos de La fundación (1976, 1979). Para completar la recepción húngara del autor más destacado del teatro español de la posguerra, repasaremos también algunos escritos que divulgan su fama en Hungría.
\end{abstract}

Palabras clave: Antonio Buero Vallejo. Recepción teatral. Hungría.

\begin{abstract}
The aim of this article is to give a comprehensive analysis about the reception of the work of Antonio Buero Vallejo in Hungary. We present the eleven translations and then, based on press criticism, analyse the five Hungarian premieres of three plays: In the Burning Darkness, staged twice (1962, 1976); The Sleep of Reason, debuted in 1974; and two premieres of The Foundation $(1976,1979)$. To complete the Hungarian image of the most prominent author of the post-civil war Spanish theatre, we also review some articles that popularized him in Hungary.
\end{abstract}

\footnotetext{
${ }^{1}$ El presente artículo se encuadra dentro de la investigación sobre la recepción del teatro español en Hungría apoyada por la Beca de investigación János Bolyai de la Academia Húngara de las Ciencias (Bolyai János Kutatási Ösztöndíj).
} 
Key Words: Antonio Buero Vallejo. Theatrical Reception. Hungary.

\section{LA OBRA DE BUERO VALLEJO ANTE EL PÚBLICO HÚNGARO}

Una lacónica necrología en la prensa húngara - hace ya veinte años, en mayo de 2000- despertó mi interés por investigar las huellas de Antonio Buero Vallejo en nuestros teatros. La noticia refería de forma escueta lo siguiente:

Buero Vallejo, dramaturgo español, falleció a sus 83 años. El autor, destacado luchador de la izquierda, fue condenado a muerte por la dictadura de Franco, pero salió de la cárcel en 1946. En 1949 se estrenó su drama más conocido, Historia de una escalera. En 1986 recibió el Premio Cervantes (“Gyászhír”, 2000)².

Conocidas la complejidad y la extensión de la producción teatral de uno de los más notables autores del teatro español, la brevedad me sorprendió y ya despertó mi sospecha de que, quizás, no encontraría muchas alusiones a Buero Vallejo en Hungría. En la primera fase de la búsqueda intenté localizar las traducciones y las puestas en escena de sus dramas, y luego también indagué sobre la crítica teatral concerniente a los pocos estrenos encontrados.

El archivo de artículos de prensa del Instituto y Museo de la Historia del Teatro Húngaro en Budapest ${ }^{3}$ guarda muchos documentos relativos a Buero Vallejo, sin embargo, la mayoría de ellos pertenece al catálogo de seguimiento de la prensa internacional ${ }^{4}$ : son informes de lectores, recortes de la prensa teatral extranjera, reseñas sobre obras y críticas de estrenos fuera de nuestras fronteras ${ }^{5}$. Todas estas informaciones iban destinadas al

\footnotetext{
${ }^{2}$ Las traducciones de los fragmentos en lengua húngara que se citan en el artículo son de mías.

${ }^{3}$ En húngaro: Országos Színháztörténeti Múzeum és Intézet, su página web: oszmi.hu. En adelante utilizaremos la abreviación OSZMI.

${ }^{4}$ Eso refleja no solamente el interés teatral de la época sino también el hecho de que funcionaba una férrea censura que seguía con vigilancia lo que se filtraba por el telón de acero.

${ }^{5}$ Las obras reseñadas son: Caimán, Diálogo secreto, Jueces en la noche, Terror, El tragaluz, Un soñador para un pueblo, Irene o el tesoro, Hoy es fiesta, Las Meninas, Las palabras en la arena, Aventura en lo gris, El concierto de San Ovidio, La doble historia de Doctor Valmy.
} 
mundillo teatral y no al público en general.

\section{TRADUCCIONES}

Rastrear las traducciones no siempre es una tarea fácil, ya que estas nacen a veces a petición de un director o un teatro. En la mayoría de los casos estos textos no serán publicados y sucede también que estas traducciones, al final, no lleguen a las tablas. Sin embargo, en casos afortunados, el archivo del OSZMI guarda un manuscrito mecanografiado, ya sea el ejemplar del traductor, del director o del teatro.

Esta constatación es válida también en el caso de Antonio Buero Vallejo, ya que tenemos más traducciones que estrenos y/o publicaciones en húngaro. Abajo, en la Tabla 1, podemos ver los datos de las traducciones que no fueron publicados en forma de libro:

\begin{tabular}{|c|c|c|c|c|}
\hline $\begin{array}{l}\text { Título original, } \\
\text { año }\end{array}$ & Título húngaro & $\begin{array}{l}\text { Año de la } \\
\text { traducción }\end{array}$ & Traductor & Formato de la publicación \\
\hline $\begin{array}{l}\text { Cartas boca } \\
\text { abajo (1957) }\end{array}$ & $\begin{array}{l}\text { Fedett } \\
\text { kártyákkal }\end{array}$ & 1961 & Péter Lengyel & $\begin{array}{l}\text { Manuscrito mecanografiado, } \\
\text { OSZMI }\end{array}$ \\
\hline $\begin{array}{l}\text { En la ardiente } \\
\text { oscuridad } \\
(1950)\end{array}$ & $\begin{array}{l}\text { Az égetö } \\
\text { sötétség }\end{array}$ & s. a. ${ }^{6}$ & Lajos Hársing & $\begin{array}{l}\text { Manuscrito mecanografiado } \\
\text { OSZMI }\end{array}$ \\
\hline $\begin{array}{l}\text { Aventura en lo } \\
\text { gris (1949) }\end{array}$ & $\begin{array}{l}\text { Kaland a } \\
\text { szürkeségben }\end{array}$ & s. a. ${ }^{7}$ & Lajos Hársing & $\begin{array}{l}\text { Manuscrito mecanografiado, } \\
\text { OSZMI }\end{array}$ \\
\hline $\begin{array}{l}\text { Historia de una } \\
\text { escalera (1949) }\end{array}$ & $\begin{array}{l}\text { Egy lépcsőház } \\
\text { története }\end{array}$ & s. a. ${ }^{8}$ & Lajos Hársing & $\begin{array}{l}\text { Manuscrito mecanografiado, } \\
\text { OSZMI }\end{array}$ \\
\hline $\begin{array}{l}\text { Hoy es fiesta } \\
(1956)\end{array}$ & Ünnep & 1964 & Sándor Tavaszy & $\begin{array}{l}\text { Manuscrito } \\
\text { mecanografiado, ejemplar } \\
\text { del traductor, archivado en } \\
\text { el OSZMI }\end{array}$ \\
\hline $\begin{array}{l}\text { El sueño de la } \\
\text { razón }(1970)\end{array}$ & Alszik az értelem & 1972 & Erzsébet Kesztyüs & $\begin{array}{l}\text { Manuscrito mecanografiado, } \\
\text { OSZMI }\end{array}$ \\
\hline
\end{tabular}

\footnotetext{
${ }^{6}$ Aunque en el manuscrito no aparece el año, del estreno —el 27 de abril de 1963 - podemos deducir la fecha de la traducción, que fue, probablemente, el año 1962.

${ }^{7}$ En este caso tampoco conocemos el año de la traducción, pero, por el autor —el mismo Lajos Hársing que tradujo En la ardiente oscuridad, en 1962- suponemos que la versión húngara nació en la década de los 60. Sarolta Réthi (1974: 27) alude al hecho de la traducción, pero sin mencionar el año en que se realizó.

${ }^{8} \operatorname{Sin}$ fecha, aunque suponemos que la versión húngara probablemente se produjo en la década de $\operatorname{los} 60$.
} 


\begin{tabular}{|l|l|l|l|l|}
\hline $\begin{array}{l}\text { El sueño de la } \\
\text { razón (1970) }\end{array}$ & Az értelem álmai & s. a. ${ }^{9}$ & György Somlyó & $\begin{array}{l}\text { Manuscrito mecanografiado, } \\
\text { OSZMI }\end{array}$ \\
\hline $\begin{array}{l}\text { La fundación } \\
\text { (1974) }\end{array}$ & Az alapítvány & 1974 & Nelli Litvai & $\begin{array}{l}\text { Manuscrito mecanografiado, } \\
\text { OSZMI }\end{array}$ \\
\hline $\begin{array}{l}\text { La doble } \\
\text { historia del } \\
\text { doctor Valmy } \\
(1968)\end{array}$ & $\begin{array}{l}\text { Valmy doktor két } \\
\text { története }\end{array}$ & 1982 & José Luis Martínez & $\begin{array}{l}\text { Manuscrito mecanografiado, } \\
\text { OSZMI }\end{array}$ \\
\hline
\end{tabular}

\section{Tabla 1. Traducciones no publicadas (manuscritos)}

Dos traducciones (Tabla 2) fueron publicadas en la revista Nagyvilág ${ }^{10}$, aunque la primera, la traducción de Somlyó, ya existía antes en forma de manuscrito, como hemos visto en la lista de arriba:

\begin{tabular}{|l|l|l|l|l|}
\hline $\begin{array}{l}\text { Título } \\
\text { original, año }\end{array}$ & $\begin{array}{l}\text { Título } \\
\text { húngaro }\end{array}$ & $\begin{array}{l}\text { Año de la } \\
\text { traducción }\end{array}$ & Traductor & Formato de la publicación \\
\hline $\begin{array}{l}\text { El sueño de la } \\
\text { razón (1970) }\end{array}$ & $\begin{array}{l}\text { Az értelem } \\
\text { álmai }{ }^{l 1}\end{array}$ & 1974 & György Somlyó & $\begin{array}{l}\text { Publicado en la revista } \\
\text { Nagyvilág, 1974. N. } .^{\circ} \text { 4. 537- } \\
591 .\end{array}$ \\
\hline $\begin{array}{l}\text { Jueces en la } \\
\text { noche (1979) }\end{array}$ & $\begin{array}{l}\text { Bírák az } \\
\text { éjszakában }\end{array}$ & 1980 & Csaba Csuday & $\begin{array}{l}\text { Publicado en la revista } \\
\text { Nagyvilág, 1980. N. } .^{\circ} 11 . \\
1633-1686 .\end{array}$ \\
\hline
\end{tabular}

\section{Tabla 2. Traducciones publicadas en revistas}

Un hito importante en la difusión de la obra dramática de Antonio Buero Vallejo fue la publicación de un tomo, con el título Drámák (Dramas), por la editorial Európa, en 1988. Para la portada se eligió una foto del estreno de El sueño de la razón (1974), en el teatro Vígszínház de Budapest $^{12}$ :

\footnotetext{
${ }_{9}^{9}$ Aunque el manuscrito de la traducción de Somlyó — guardado en la biblioteca del OSZMI — no tiene fecha, podemos suponer que se produjo en 1973 para el estreno del 9 de mayo de 1974. La biblioteca conserva dos ejemplares: uno del traspunte y otro del apuntador del espectáculo.

${ }^{10}$ Revista literaria, fundada en 1956, dedicada a la publicación de traducciones y a la difusión de la literatura extranjera en Hungría.

${ }^{11}$ Podemos ver, pues, que de El sueño de la razón existen dos versiones húngaras: la primera, traducida en 1972 por Erzsébet Kesztyüs, y la segunda, traducida dos años más tarde por György Somlyó.

${ }^{12}$ En la foto aparece el actor Gyula Mádi Szabó, en el papel de Goya.
} 


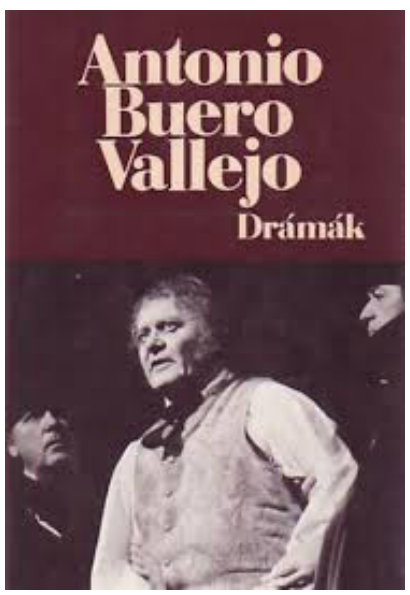

Figura 1. Portada de Drámák

La antología contiene cinco dramas (Tabla 3), con selección de Ferenc Szőnyi, el traductor de la primera pieza del tomo:

\begin{tabular}{|l|l|l|}
\hline Título original, año & Título húngaro & Traductor \\
\hline Un soñador para un pueblo & A népboldogító & Ferenc Szőnyi \\
\hline El sueño de la razón & Alszik az értelem & Erzsébet Kesztyüs \\
\hline La fundación & Az intézet & János Benyhe \\
\hline Jueces en la noche & Bírák az éjszakában & Csaba Csuday \\
\hline Caimán & A kajmán & Csaba Csuday \\
\hline
\end{tabular}

Tabla 3. Traducciones publicadas en libro

Como podemos ver, entre las cinco piezas aparecieron tres que ya habían sido traducidas anteriormente. En el caso de El sueño de la razón, la obra se tradujo en 1972 (con el título Alszik az értelem) y en 1974 (con el título $A z$ értelem álmai). Para la publicación, la editorial eligió la primera versión, o sea, la traducción de Erzsébet Kesztyüs. Eso es curioso por dos motivos: por un lado, porque György Somlyó ${ }^{13}$ era poeta, escritor,

\footnotetext{
${ }^{13}$ Aunque tradujo mucho más de la literatura francesa (Racine, Hugo, Balzac, Lamartine, Valéry, Rimbaud, Gide, Aragon), son notables también sus traducciones de la literatura hispanoamericana (Piedra de sol, de Octavio Paz; El otro, el mismo, de Jorge Luis Borges; varios tomos de Pablo
} 
ensayista y un traductor literario mucho más famoso y reconocido que su colega, Erzsébet Kesztyüs ${ }^{14}$; por otro, hay que destacar también que, para el estreno de 1974, en el Vígszínház, de donde se toma la foto para la portada de la antología, el director utilizó el texto de Somlyó.

En el caso de la La fundación, podemos ver que el editor del tomo publicó una retraducción, con trabajo de János Benyhe, y no la primera versión, la de Nelli Litvai, del año 1974. Además, el título de la traducción es también diferente: Az alapitvány (1974) y Az intézet ${ }^{15}(1988)^{16}$.

El tercer drama, Jueces en la noche, fue publicado, como hemos visto ya, en la revista Nagyvilág y, en este caso, el traductor fue Csaba Csuday. Es interesante además que la editorial no publicase en este tomo otras traducciones ya existentes (Cartas boca abajo, En la ardiente oscuridad, Aventura en lo gris, Historia de una escalera, Hoy es fiesta, La doble historia del doctor Valmy), aunque inaccesibles para un público más amplio. Sin embargo, en el tomo de 1988 hay dos novedades respecto a los manuscritos encontrados en el archivo del OSZMI: Un soñador para un pueblo y Caimán.

Otro detalle curioso de esta antología dramática es que no tiene ni prólogo ni epílogo, solamente un breve texto en la solapa orienta a los lectores sobre el autor y su obra:

Antonio Buero Vallejo es la figura más interesante y más talentosa de la generación de los dramaturgos del periodo posterior a la Segunda Guerra Mundial. Es maestro del teatro realista mezclado con elementos existencialistas, de la construcción dramática más bien tradicional [...], de las finas sugerencias y de la brillante

\footnotetext{
Neruda) y de la española (poemas de Miguel Hernández y de Federico García Lorca, y Yerma, drama de García Lorca). Además, escribió una obra biográfica sobre Pablo Picasso (Somlyó, 1981). 14 Entre las traducciones de Erzsébet Kesztyüs cabe mencionar algunas narraciones breves y novelas de la prosa hispanoamericana (Miguel Ángel Asturias, Mario Vargas Llosa, Gabriel García Márquez, Manuel Puig y Salvador Garmendia).

15 La palabra intézet tiene más bien el significado de centro o instituto, mientras que alapítvány equivale a fundación.

16 Cabe destacar que en los dos estrenos húngaros de La fundación (en 1976 y en 1979), los dos directores utilizaron la traducción de János Benyhe. De esta información podemos deducir que su traducción nació ya mucho antes de la publicación en el tomo de 1988. Es curioso, pero, que el título de los estrenos fue Az alapitvány, pues el título que apareció también en la primera traducción de Nelli Litvai y no Az intézet, versión de Benyhe, en el tomo publicado por la editorial Európa.
} 
técnica escénica. Los teatros por todo el mundo estrenan sus obras con gusto y mucho éxito. Incluso en nuestra patria hubo, gracias a él, más ardientes noches de teatro. Las piezas publicadas en el presente tomo [...], en su mayoría, son obras nuevas, entre ellas dos (El sueño de la razón, La fundación) fueron estrenadas en el Vigszínház y en Kaposvár durante mucho tiempo y con mucho éxito (Buero Vallejo, 1988: solapa anterior).

Podemos constatar que en el texto se olvida mencionar incluso la nacionalidad del dramaturgo, una información mínima pero obligatoria para los que tengan pocos conocimientos de la historia del teatro extranjero. Así, leyendo esta solapa, un lector húngaro ni siquiera llega a saber que se trata de un autor español. Otra deficiencia de esta "introducción" es que pasa también por alto el Premio Cervantes, un galardón importante, concedido a Buero Vallejo en 1986, un hecho seguramente conocido por el editor.

Junto a estos defectos podríamos preguntarnos aún: ¿qué motivó la decisión editorial de omitir un prólogo o un epílogo? No conocemos la respuesta concreta, sin embargo, un artículo de Imre Gergely, publicado en la revista Film Színház Muzsika, en 1989, nos ofrece una posible explicación. Partiendo de este escrito llegamos a conocer que la editorial Európa tenía el proyecto sobre el tomo de Buero Vallejo ya en 1986 y encargó a Imre Gegely que escribiera un epílogo a la colección de cinco dramas. El crítico de teatro cumplió con el trabajo, envió su ensayo a la editorial y, sin embargo, en la edición de 1988 no fue publicado. Es más: la Európa ni siquiera informó a Gergely de la publicación del tomo. Buscando una explicación, el crítico supone que, quizás, la editorial quisiera evitar la mención del perfil marxista del dramaturgo español, y por tanto optara por omitir el epílogo. Es una pena, ya que, como escribe Gergely, "una antología sin prólogo [o epílogo] no es comerciable. Los empleados no pueden ofrecer a los lectores, los ejemplares son invendibles y quedan en las librerías" (Gergely, 1989). Por eso, Imre Gergely escribe su artículo al que aún vamos a volver después de reseñar los estrenos húngaros - para rellenar el hueco que dejó el epílogo olvidado de la antología dramática de 1988.

Resumiendo, podemos ver que en total tenemos once obras de Buero Vallejo traducidas al húngaro (Cartas boca abajo, En la ardiente 
oscuridad, Aventura en lo gris, Historia de una escalera, Hoy es fiesta, El sueño de la razón, La fundación, La doble historia del doctor Valmy, Jueces en la noche, Un soñador para un pueblo, Caimán), de las cuales cinco fueron publicadas en un tomo (Buero Vallejo, 1988), dos en una revista literaria (Nagyvilág, n. ${ }^{\circ} 4$ de 1974; n. ${ }^{\circ} 11$ de 1980) y solo tres llegaron a las tablas. Las otras traducciones se quedan olvidadas bajo una leve capa de polvo en los anaqueles de la biblioteca del OSZMI, esperando a que un director y una compañía teatral las descubran y pongan en escena ${ }^{17}$.

\section{TRES OBRAS, CINCO ESTRENOS}

En la historia de la recepción húngara del teatro bueriano se destacan los estrenos de tres obras, con cinco fechas que resumimos en la Tabla 4:

\begin{tabular}{|l|l|l|l|}
\hline Obra estrenada & Fecha & Teatro (ciudad) & Director \\
\hline $\begin{array}{l}\text { Az égetö sötétség } \\
\text { (En la ardiente oscuridad })\end{array}$ & $27 / 04 / 1963$ & Universitas Együttes (Budapest) & Vilmos Dobai \\
\hline $\begin{array}{l}\text { Az értelem álmai } \\
\text { (El sueño de la razón) }\end{array}$ & $09 / 05 / 1974$ & Vígszínház (Budapest) & László Marton \\
\hline $\begin{array}{l}\text { Az égetö sötétség } \\
\text { (En la ardiente oscuridad })\end{array}$ & $14 / 02 / 1976$ & Ódry Színpad (Budapest) & Vilmos Dobai \\
\hline $\begin{array}{l}\text { Az alapitvány } \\
(\text { La fundación })\end{array}$ & $05 / 03 / 1976$ & Csiky Gergely Színház (Kaposvár) & $\begin{array}{l}\text { László } \\
\text { Babarczy }\end{array}$ \\
\hline $\begin{array}{l}\text { Az alapitvány } \\
(\text { La fundación })\end{array}$ & $04 / 03 / 1979$ & $\begin{array}{l}\text { Tamási Áron Színház } \\
\text { (Sepsiszentgyörgy) }\end{array}$ & $\begin{array}{l}\text { Attila Seprődi } \\
\text { Kiss }\end{array}$ \\
\hline
\end{tabular}

Tabla 4. Estrenos

Podemos ver, pues, que la llegada de Buero Vallejo a nuestros teatros es bien tardía: solo en 1963 aparece su nombre por primera vez, en el cartel de En la ardiente oscuridad, que fue estrenada por una compañía aficionada, compuesta por estudiantes universitarios ${ }^{18}$. La misma obra

\footnotetext{
${ }^{17}$ De la lista de las traducciones no puede faltar un breve texto teórico - mejor dicho, solo extractos de este- de Buero publicado en el tomo Realizmus a színházban (Realismo en el teatro), en la edición de Judit Sz. Szántó (1966). Junto a Buero, la editora del libro seleccionó también unos fragmentos de Alejandro Casona y Lauro Olmo.

${ }^{18}$ Cabe notar que no fue la primera vez que esta obra despertaba el interés de los estudiantes. La elección de esta obra por jóvenes estaba motivada, sin duda alguna, también por el escenario y los personajes, ya que la acción se desarrolla en un colegio para estudiantes ciegos. Véase, por ejemplo,
} 
volverá trece años más tarde, en 1976, y es curioso que de nuevo en una escena semiprofesional, ya que esta vez los estudiantes de la Universidad de Arte Dramático y Cinematográfico ${ }^{19}$ de Budapest eligieron esta obra para hacer el examen final.

El verdadero reconocimiento para Buero Vallejo llegó en 1974 con el estreno de El sueño de la razón, en el Vígszínház ${ }^{20}$ de Budapest, es decir, en un teatro prestigioso y de mucha historia. El número de reseñas y críticas refleja bien la importancia y el éxito del espectáculo.

A pesar de eso no se produjo un rompimiento: en la misma década solo un drama más fue presentado en la escena húngara, y este fue $L a$ fundación, del que hubo dos estrenos, ambos en teatros de provincia. El primero fue en $1976^{21}$, en Kaposvár, y el segundo, en 1979, en Sepsiszentgyörgy, en una ciudad de Rumanía, pero con un teatro de lengua húngara $^{22}$. Esta fue, hasta 2019 — año en que termina mi búsqueda - la última puesta en escena en húngaro de una obra bueriana.

\subsection{En la ardiente oscuridad: estrenos de 1963 y 1976}

En la ardiente oscuridad, estrenada en Madrid el 1 de diciembre de 1950, en el teatro María Guerrero, llegó a Hungría en 1963. La segunda vez fue puesta en escena en 1976, sin embargo, la traducción no fue editada en el tomo de los dramas de Buero Vallejo, de 1988.

En el archivo del OSZMI podemos encontrar una reseña sobre este drama, escrita por Lajos Hársing, el traductor de la obra. Aunque las cuatro hojas mecanografiadas no llevan fecha, es de suponer que el escrito nació antes del estreno, o sea, antes de 1963. Después del resumen del contenido, el traductor escribe su valoración:

La acción se desarrolla en un ambiente insólito pero muy acertado. La verdad y los profundos sentimientos humanos reflejados en la

otro estreno en la University of Missouri, en 1969 ("Director Calls Play 'Symbolic", 1969).

${ }^{19} \mathrm{En}$ aquel entonces la universidad funcionaba como escuela superior, en 2000 recibió el rango de universidad.

${ }^{20}$ Es uno de los más antiguos (fundado en 1896) y más populares teatros de la capital húngara, con una capacidad de 1700 espectadores

${ }^{21}$ Es decir, en 1976 hubo dos obras puestas en escena de Buero con un solo mes de diferencia entre los estrenos.

${ }^{22} \mathrm{El}$ motivo es que casi el $80 \%$ de la población es húngara. 
obra son válidos para toda la sociedad. La búsqueda de lo mejor triunfa aunque el primer portador de la ideología queda silenciado. La obra está compuesta por actos muy rápidos y expresivos incluso con pocas palabras. El desenlace no se transluce hasta el tercer acto y solamente en este momento se entiende el mensaje más profundo y más hermético del drama. [...] En cuanto al papel de los actores, es una obra interesantísima y extremamente dificil, y desde el comienzo hasta el fin es muy emocionante [...] (Hársing, s. a.: 4).

Una semana antes del estreno, el mismo Hársing publicó un artículo en una revista estudiantil para despertar el interés del público. En él destaca que en el drama de Buero se desarrolla un juego entre la realidad y lo simbólico con el lenguaje de una dramaturgia puritanamente simple. Después de resumir la acción, la revista publica también un fragmento de la traducción, el primer enfrentamiento entre Ignacio y Carlos (Hársing, 1963).

La primera crítica después del estreno escrita por "f. f." ${ }^{23}$ subraya que detrás de la superficie es bastante fácil ver la tragedia del pueblo español y observar una triste y casual actualidad: el asesinato de uno de sus héroes de la libertad. Aunque el reseñador no escribe concretamente el nombre de este "héroe asesinado", es obvio que se trata de Julián Grimau, fusilado el 20 de abril del mismo año, o sea, siete días antes del estreno húngaro de En la ardiente oscuridad. Destaca además que la censura fue la que obligó al dramaturgo a crear un sistema de símbolos para transmitir un mensaje trasladado. Este mensaje "más allá de la acción" fue sugerido perfectamente, sin didactismo forzado, por la dirección de Vilmos Dobai (f. f., 1963).

Otro artículo, publicado en una revista literaria importante, llama también la atención al paralelismo entre el centro de los ciegos y España, y llega a la conclusión de que la verdadera tragedia no es la ceguera física, sino la imposibilidad de percibir la realidad. Ignacio representa al hombre rebelde que es incapaz de vivir según las reglas antiguas. "En él está el germen de la revolución y, a pesar de su caída, vence la guerra" (Hámos, 1963), escribe el crítico. Elogia también a los estudiantes que actúan disciplinadamente, y cuya falta de rutina es perceptible solamente

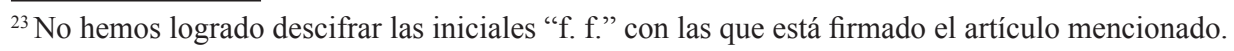


en las reacciones precipitadas de la parte final. Según su opinión, esta obra tendría éxito merecidamente.

La valoración más extensa sobre la primera escenificación de En la ardiente oscuridad se publicó en la revista universitaria Egyetemi Lapok. El autor del artículo, Géza Fodor, al igual que el crítico que firma con las iniciales "f. f.", alude al martirio de Grimau, pero esta vez sí que escribe su nombre: "El recuerdo doloroso de Julián Grimau prestó dramático esplendor al espectáculo" (Fodor, 1963). Hablando sobre los dos niveles - el concreto y el simbólico - del drama, compara el colegio a una jaula de oro donde los ciegos mienten a sí mismos una vida normal. Este mundo ilusorio proporciona una existencia harmónica para los internados $\mathrm{y}$, en su caso, la mentira tiene efecto curativo. Si alguien quiere destruir las ilusiones, su ambición será deshumana, ya que rompe la unidad de una comunidad y empuja a sus miembros a la incertidumbre. Si la colectividad es suficientemente fuerte, echa fuera al individuo destructivo, de modo que el fracaso de Ignacio es necesario y reconfortante. Sin embargo - sigue Fodor - la jaula, aunque es de oro, es cárcel y hay que romperla. La obra tiene un significado evidentemente político, pero el crítico opina que "el sentido concreto y el simbólico no corren paralelamente, sino que se enfrentan" y eso es "dramatúrgicamente un salto mortale". Reconoce los méritos de la dirección de Vilmos Dobai, que logró "realizar un espectáculo equilibrado, un verdadero juego en equipo ${ }^{24 "}$ y cumplió el axioma de Sándor Hevesi ${ }^{25}$ según el cual "el director muere en el actor". Una dirección no puede recibir mayor elogio, concluye Fodor. El único aspecto negativo lo encuentra en la traducción de Lajos Hársing que, según la opinión del crítico, "parecía un poco cruda y como si el uso de palabras no fuera siempre consecuente" (Fodor, 1963). No obstante, en la reseña llevada a cabo por alguien que firma como "l-x"26, podemos encontrar una opinión opuesta a la de Fodor en cuanto a la valoración del trabajo del traductor y tilda el texto húngaro de muy poético (1-x, 1963).

Como detalle sorprendente mencionaría que en dos artículos

${ }^{24}$ El equipo fue compuesto por Tibor Kristóf (Ignacio), László Breyer (Carlos), Katalin Csaplár (Elisa), Sári Faragó (Juana), Éva Benkő (Doña Pepita), József Kelemen (Don Pablo), Tamás Jordán (Miguelín).

${ }^{25}$ Sándor Hevesi (1873-1939), director, dramaturgo, crítico, escritor traductor, profesor y director de teatro húngaro. Escribió importantes textos teóricos sobre el teatro.

${ }^{26}$ No hemos logrado descifrar las iniciales "l-x". 
podemos encontrar fallos ortográficos en el nombre del dramaturgo español: Guero en vez de Buero (1-x, 1963) y Valleyo ([A.], 1963), en lugar de Vallejo. Creo que eso es una grave negligencia por parte de los críticos.

A pesar de que en 1974 fue presentada otra obra de Buero - a cuya repercusión en la prensa teatral vamos a volver más adelante-, ahora hacemos un salto cronológico en la recepción y seguimos aún con En la ardiente oscuridad. Trece años después de la primera puesta en escena, en 1976, otro grupo de estudiantes eligió la obra como estreno de examen para escenificarla en el teatro Ódry ${ }^{27}$. Es interesante que la crítica de esta producción fuese muy ambigua. Por un lado, encontramos opiniones positivas que elogian el trabajo del director Vilmos Dobai (el mismo que trabajó con el otro grupo de estudiantes en 1963), constatando "que logró formar un espectáculo interesante en el que se acentúa la importancia de la alteración forzada de los sentidos" (N. J., 1976). El mismo crítico destaca la coreografía del movimiento de los actores, en la que los invidentes podían moverse casi sin obstáculos. De los jóvenes actores el artículo menciona a Balázs Blaskó, en el papel de Ignacio, cuya rebelde figura es radiante, y a László Vitéz, como Carlos, un personaje duro y pujante, que se convierte en "el nuevo Ignacio" tras la muerte del primero. Por otro lado, podemos leer una opinión completamente opuesta a la antes citada. Por ejemplo, según Bogácsi, "el espectáculo fue indiferente y mediocre" (1976), aunque el drama es perfecto tanto para la identificación con el mensaje como para mostrar la experiencia en la profesión actoral. Sin embargo — sigue la crítica menos positiva - Vilmos Dobai "no determinó los focos, el desarrollo y el ritmo de los conflictos" y dejó demasiada libertad en cuanto a la actuación de los estudiantes. Bogácsi tampoco ofrece una buena valoración sobre el trabajo de los jóvenes actores y opina que "el único que lleva en sus hombros todo el espectáculo es el Ignacio de Balász Blaskó, sus rivales son insignificantes". El crítico concluye que "no hay equilibrio dramatúrgico, las ideas son pálidas y el espectáculo muestra nada más que la crisis en un colegio" (Bogácsi, 1976). En el periódico Magyar Ifjúság también se publicó una reseña (de autoría desconocida) bastante negativa: "El director y el traductor son los mismos del estreno de trece años antes, sin embargo, de este espectáculo falta lo político y lo actual, que fue uno de

${ }^{27}$ Desde 1959 este teatro da espacio a los espectáculos de examen de los estudiantes de la Universidad de Arte Dramática y Cinematográfica de Budapest. 
los méritos de la primera puesta en escena. [...]" (“Égető sötétség”,1976). En otras reseñas podemos leer también una opinión semejante, o sea, que la interpretación de la ceguera es más acentuada que el mensaje simbólicopolítico, apreciado por la crítica en el espectáculo de 1963. "Como práctica profesional es excelente, pero no es una producción teatral con mensaje actual", concluye la reseña no firmada.

\subsection{El sueño de la razón (1974)}

El sueño de la razón, drama estrenado el 6 de febrero de 1970, en el Teatro Reina Victoria de Madrid, despertó mayor interés en la vida teatral húngara que el estreno de En la ardiente oscuridad, tanto por parte del público como por parte de la crítica. Eso fue motivado sobre todo por el hecho de que un teatro de Budapest de mucho prestigio pusiese la obra en su repertorio en la temporada 1973/74. Después del estreno - que se produjo el 9 de mayo de 1974- se publicaron numerosos artículos (reseñas breves y críticas más profundas) en diferentes periódicos y revistas, y eso ya en sí refleja bien la resonancia de la pieza. Antes del estreno, en una entrevista, el director, László Marton, declaró que iba "a dirigir el drama más hermoso de los últimos años" (en Pintér, 1974). Las expectativas, pues, eran muy altas.

Visto que el debut húngaro de Buero en 1963 no llamó demasiado la atención del público, los espectadores sabían muy poco sobre el dramaturgo español. Así, para reparar esta deficiencia, casi todas las reseñas de 1974 aluden a datos biográficos del dramaturgo (sus estudios de pintura en la Escuela de Bellas Artes de San Fernando, los años pasados en cárceles franquistas, el Premio Lope de Vega) y ofrecen un breve análisis de su obra dramática, citando sus títulos más conocidos. No falta tampoco la mención a que sus obras fueron traducidas, publicadas y estrenadas en varios países del mundo. En el caso de El sueño de la razón, destacan que la escenificación húngara se realizase después de los estrenos en Italia, en Rumanía, en la RDA y en la URSS.

Junto a la biografía del dramaturgo, muchos críticos sentían la obligación de presentar en algunas líneas también la vida de Francisco Goya, inspirador de la pieza. Subrayan que los comienzos profesionales de Buero determinaron más tarde su afición por la pintura, que se manifestaba no solamente en El sueño de la razón, sino también en Las Meninas 
(1960), cuyo protagonista era Diego Velázquez y que era anterior al drama sobre Goya. András Rajk empieza su artículo con una alabanza de la obra artística de Goya "cuya vida fue, de verdad, para escenificarla" (1974). Ervin Szombathelyi (1974) incluso cita unos párrafos de la biografía de Goya escrita por Lion Feuchtwanger, que los lectores húngaros podían leer en traducción. Szombathelyi resalta, sin embargo, que la obra no es una biografía del famoso pintor español sino que el dramaturgo condensa su propio mensaje sobre el ser humano, el mundo y la libertad artística en una situación vital. Justamente por el conocimiento de la biografía de Goya, Vera Létay le reprocha al autor la contradicción entre el carácter del pintor del drama y el verdadero:

Goya fue un hombre robusto, un campesino de pocas palabras que se expresaba dificilmente. Sin embargo, el Goya de Buero habla en un lenguaje elocuente, y analiza su relación con los monstruos, las creaciones de su propia fantasía, como si fuera un crítico sofisticado que está preparando una disertación sobre las pinturas negras de Goya (Létay, 1974).

Algunos críticos valoran el drama simplemente como una pieza histórica y biográfica y no ven - o no quieren ver - paralelismos entre la represión de Fernando VII y otras dictaduras más actuales. Por ejemplo, para Zoltán Lökös, la obra "refleja la tragedia personal de Goya" y, aunque el crítico reconoce que "es posible una interpretación más amplia y general", escribe que "a eso no hay alusión directa" (1974). László Possonyi, sin embargo, llama la atención sobre el paralelo entre el pasado y el presente y ve claramente la parábola: "Los falangistas están allí, solo llamados como voluntarios del rey” (1974). Tamás Koltai también resalta que, a pesar de la superficie histórica, la obra de Buero es un drama político en el que "el autor muestra la lucha entre el poder reaccionario y un artista progresista y liberal" (1974a). En su conflicto - sigue Koltai — podemos sentir el drama de la España actual. A pesar de eso, la crítica final de Koltai es negativa porque opina que Buero no logra realizar su objetivo: "la minuciosidad del texto a la manera barroca resulta un drama lleno de efectismo, lo que sobrepasa la idea misma" (1974a).

Ottó Major tiene un dilema al definir de qué trata la obra: "En general: ¿sobre el conflicto entre el poder y el arte? ¿O sobre el arte de Goya? 
¿O sobre la tragedia del pueblo español?” (1974), se pregunta. A pesar de la multiplicidad de preguntas, el crítico de la revista Tükör opina que todo lo que recibimos de la obra "se pierde en la confusión de la proyección de los cuadros y alucinaciones" (Major, 1974). La fantasía de Buero - sigue Major - trata del miedo, sin embargo, "no ofrece nada más que una espectacular y a veces estridente presentación del terror" (1974). Seguro que el naturalismo del terror de la escenificación motivó a Létay a definir el género de la obra "como una mezcla de drama histórico simplificado y un Grand Guignol" (1974). Es interesante también la constatación de Barta que afirma que "el drama sigue el modelo de Brecht, fue escrita en un estilo didáctico" (1974). Barta define el género del drama "como un ensayo de historia del arte narrado en un lenguaje teatral" (1974). Este crítico opina que el mayor error de la construcción dramática de la obra de Buero es que no se realiza el encuentro personal entre el poder y el artista. Además, sigue Barta, encontramos otra deficiencia en el retrato de la figura del pintor, ya que Buero resalta solamente la tenacidad y el miedo del personaje.

Es bien conocido que Buero Vallejo en varias obras aprovecha las taras físicas de sus personajes para lograr la inmersión de los espectadores. Basta pensar en la ceguera de los personajes de En la ardiente oscuridad o de El concierto de San Ovidio, cuya manifestación escénica se produce a través del uso de la oscuridad total en determinados momentos. En el drama sobre Goya es la sordez la que determina el juego escénico, ya que cuando el pintor está en la escena, nosotros tampoco escuchamos la voz de los otros, y sabemos que están "hablando" solo del movimiento de sus labios y de sus gestos. La opinión de los críticos húngaros sobre el uso de esta técnica era divergente. Hubo algunos que elogiaron su originalidad, constatando que gracias a sumergir a los espectadores en el silencio lleno de ruidos y fantasmas de Goya, "la identificación con el héroe se produjo en seguida" (Szalontay, 1974). Rajk también alaba "la brillante técnica dramatúrgica" que expresa perfectamente el mundo interior de un sordo y cuyo efecto "casi persigue a los espectadores al universo del pintor anciano lleno de visiones" (1974). Gyula Pintér escribe lo siguiente: "siento como si yo también estuviera sordo, y así percibo las cosas a través de la conciencia del pintor" (1974). Zoltán Lökös considera que "el silencio es también el del miedo que lo envuelve todo en el imperio de la represión, donde está prohibido hablar" (1974). Jenő Illés reconoce el mérito de la 
técnica original de Buero, diciendo que "gracias a esta pieza española, el público húngaro puede descubrir un nuevo mundo dramatúrgico” (1974). Por otro lado, sin embargo, hemos encontrado también opiniones menos positivas en cuanto al uso de esta técnica de inmersión del público en la sordez. Vera Létay considera que "lamentablemente la obra se detiene en puro formalismo. El autor construye su obra en torno a la sordez de Goya, y utiliza la enfermedad no simplemente como motivo psíquico sino también como una eficaz idea dramatúrgica" (1974). La opinión de Koltai es totalmente negativa: el juego mudo no solo silencia sino que "ahoga por completo las situaciones más dramáticas” (1974a), y la gesticulación no logra mantener la tensión, es aburrida. "El lenguaje de signos durante dos horas carga mucho los nervios de los espectadores", escribe también Possonyi (1974). Otto Major expresa una opinión semejante, diciendo sin rodeos que "el juego mudo es absolutamente antiteatral" (1974) y es una tarea dificilísima tanto para el director como para los actores. La técnica de la proyección de los cuadros de Goya también recibe valoraciones divergentes. Unos opinan que son ilustraciones de la biografía del pintor, mientras que otros consideran que las pinturas no ilustran simplemente la historia sino que llevan adelante la situación (Illés, 1974) ${ }^{28}$.

La valoración de la actuación de los actores fue, en general, positiva, y sobre todo el protagonista, Gábor Mádi Szabó, pudo cosechar palabras elogiadoras. Según dos críticos, el papel de Goya fue uno de sus mayores y mejores actuaciones (Rajk, 1974; Szombathelyi, 1974). Szalontay (1974) opina que "Mádi Szabó interpretó el temperamento y la fuerza moral del gran genio de la pintura con una enorme tensión interna". "Su carisma determina toda la atmósfera del espectáculo", escribe Illés (1974).

Otro personaje importante del drama es Leocadia, interpretada por Éva Pap. Los críticos alaban su actuación, destacando que incluso sin palabras puede mostrar una mujer sensible, sus emociones son auténticas (Létay, 1974) e interpreta fielmente el martirio de una mujer quebrada (Possonyi, 1974). Sin embargo, hay algunos que opinan que el carácter de

\footnotetext{
${ }^{28}$ Un curioso detalle del estreno de la obra en Madrid fue que proyectaron las pinturas de Goya fotografiadas por Juan Gyenes, gran fotógrafo de origen húngaro (véase la crítica de Lorenzo López Sancho, 1970: 63, después del estreno madrileño). Gyenes fotografió más veces también los espectáculos de las obras de Buero (véase las fotos en la Índice de ilustraciones del artículo de Virtudes Serrano, 2016).
} 
la actriz es más delicado y frágil de lo que Buero había imaginado para la figura de la concubina de Goya (Koltai, 1974a; Barta, 1974).

Géza Tordy, en el ropaje de Fernando VII, "resaltó perfectamente la esencia de un déspota cínico y enfermizo" (Lőkös, 1974). Justamente este cinismo provocó el disgusto en otro crítico: "su sonrisa es demasiado irónica" (Szalontay, 1974). En la interpretación de Tordy, "el rey es un hombre afeminado que es diferente del monarca sugerido por las instrucciones de Buero, sin embargo, su actuación fue impresionante" (Koltai, 1974a). Sobre la interpretación de Tordy, Létay tiene una valoración muy negativa: "se suelen interpretar así a un imitador de mujeres en un cabaret de Nochebuena" (1974), constata. Una opinión completamente opuesta a la anterior tiene László Possonyi, que alaba a Tordy y llega a la conclusión de que "él fue el eje del espectáculo" (1974).

Los críticos destacaron también el espacio escénico simple y funcional (Szalontay, 1974; Koltai, 1974a) diseñado por Miklós Fehér, que contribuyó perfectamente a aumentar la tensión de la obra (Illés, 1974). El vestuario (Mária Jánoskúti), según Illés (1974), expresa fielmente la época de Fernando VII y las máscaras de los demonios (diseñadas por Iván Koós) reflejan bien las visiones internas de Goya. Otro crítico percibió de otra manera estas máscaras:

Estas figuras no se parecen a los monstruos, son más bien unos amistosos animales domesticados. No espantan sino que emanan un cariño grotesco. Como si un dibujante un poco ebrio hubiera diseñado a la bruja tres pechos en vez de dos $y$, por confusión, alas de murciélago en lugar de las orejas (Létay, 1974).

Los reseñadores alaban la música de Frigyes Hidas, que tenía una función dramatúrgica en la escenificación (Szombathelyi, 1974). El traductor del drama, György Somlyó también recibió una crítica positiva en la prensa teatral, aunque, como constata Possonyi (1974), debido al amplio juego mudo es difícil valorar el trabajo del traductor sin conocer el texto.

En cuanto a la conclusión final y el trabajo del director, László Marton, podemos encontrar críticas tanto positivas como negativas. Entre las primeras, cito las palabras de Mihály Szalontay: "Merecía la pena el estreno: el mensaje limpio y noble de la obra se formula en soluciones 
dramatúrgicas y escenográficas muy originales" (1974). Lökös también elogia la interpretación correcta de la escenificación y concluye que "el director está en simbiosis con el dramaturgo" (1974). Según Rajk, el estreno fue "el espectáculo más conmovedor de la temporada" (1974). Szombathelyi también expresa la misma opinión: "vimos un espectáculo lleno de valores" (1974).

Sin embargo, no todos están de acuerdo con los anteriores. Koltai escribe que "Marton tachó mucho del texto y con eso se pierde la teatralidad del drama" (1974a). Según Létay, en las tablas del Vígszínház "vimos la siesta de la razón dormidera [...] y las bestias, los demonios y los monstruos verdaderos no salieron; quedaron en las paredes del Prado, en la noche de Goya y en la realidad" (1974a). Parece que el resultado tampoco satisface a Illés porque escribe que "Marton habría tenido que prestar mayor atención a las sugerencias del texto bueriano para crear un mundo escénico más íntimo y matizado" (1974). Según la opinión de este crítico, el director pone en escena la tragedia humana en su extrema crueldad y naturalismo, pero no logra expresar los sentimientos más sutiles que se manifiestan en el cambio de ritmo del latido del corazón. La dirección de Marton — sigue Illés - es fiel y a la vez infiel a la obra de Buero Vallejo. Vera Létay tenía una impresión semejante: "Es difícil descifrar los secretos psicológicos de la creación artística con la mezcla del drama histórico y el extraño ballet de animales" (1974). Otra valoración negativa nació de la pluma de Barta: "el drama representa el mundo de las moralejas con la tradicional inflexibilidad de los dramas didácticos; por eso, en el público despierta más bien un interés que es propio de un buen estudiante y no una verdadera y agitada compasión" (1974).

El ya citado Koltai, al analizar otros estrenos de dramas extranjeros - entre los que se incluye El sueño de la razón - constata que lamentablemente estos no podían convertirse en obras húngaras, o sea, no podían asimilarse, a pesar de las traducciones excelentes, a la cultura húngara. "El drama sobre Goya no es más que una biografía del pintor ilustrada con diapositivas" (Koltai, 1974b).

Otto Major también coloca el estreno de El sueño de la razón en un contexto más amplio, comparando su realización escénica con direcciones de obras de Moliére y Chejov, y hace un balance de toda la temporada del Vígszínház: 
Examinando todo el trabajo del teatro podemos llegar a la siguiente conclusión: el Vigszínház, en esta temporada, se convirtió en el teatro del miedo y de la angustia. El espiritu del miedo y de la angustia impregnó tanto el estreno de La escuela de mujeres como el de El jardín de los cerezos. Eso incita a la reflexión. ¿Por qué? ¿Qué quieren sugerir? Y, sobre todo, ¿exige eso el público? Según mi opinión, se necesitan más bien estrenos como fue La cuadratura del círculo, comedia de Katajev en la temporada anterior, o El festival Pop ${ }^{29}$ (Major, 1974).

El crítico de la revista Vigilia hace una constatación que descubre un detalle interesante no solamente de la acogida de El sueño de la razón, sino de toda la recepción del teatro español en Hungría: "La puesta en escena de los dramas españoles es una tarea difícil para los directores húngaros" (Possonyi, 1974).

\subsection{La fundación $(1976,1979)$}

Como hemos visto antes, En la ardiente oscuridad y El sueño de la razón llegaron a las tablas húngaras con una tardanza de trece y cuatro años respectivamente, si consideramos su debut en España. En el caso de La fundación —drama estrenado por primera vez el 15 de enero de 1974, en el Teatro Fígaro de Madrid, bajo la dirección de José Osuna - el público húngaro no tuvo que esperar tanto: la primera traducción surgió en el mismo año del estreno español, o sea, en 1974, de la pluma de Nelli Litvai. Sin embargo, esta primera traducción se quedó olvidada en el archivo del OSZMI y los directores de los dos estrenos húngaros de esta pieza utilizaron otra traducción, la de János Benyhe, realizada probablemente en 1975 y publicada en el tomo de 1988, con el título Az intézet.

El primer estreno de La fundación (en húngaro: Az alapítvány) fue el 3 de marzo de 1976, en el teatro Csiky Gergely de Kaposvár. Este teatro, aunque en una ciudad de la provincia, a unos 190 kilómetros de la capital húngara, albergó a una de las compañías determinantes de la vida teatral

\footnotetext{
${ }^{29}$ El primer musical húngaro de Gábor Presser y Anna Adamis basado en la novela homónima de Tibor Déry. El título entero: Képzelt riport egy amerikai popfesztiválról (Reportaje imaginario sobre un festival pop estadounidense).
} 
húngara entre 1970 y 2000. Por eso, los críticos de Budapest siempre seguían con atención los eventos de Kaposvár, como muestra también la resonancia de La fundación en la prensa teatral. Es interesante que incluso el telediario de la noche del 5 de marzo de 1976 - dos días después del estreno - informase a los telespectadores sobre la obra:

Es un psicodrama político en el que Vallejo construye a partir de sus propias experiencias vividas en la cárcel la parábola de la situación actual de los intelectuales de la izquierda de la Europa occidental. El escritor, el ingeniero, el matemático, el artista y el médico son hombres creadores y luchadores. La fundación no puede comprar su libertad y asi todos serán víctimas de este mundo brutal (“Az alapítvány”, telediario, MTV, 19:30 horas, 5 de marzo de 1976).

Tres días después del estreno se publicó una entrevista con el director, László Babarczy cuyas palabras son como una recomendación para despertar el interés del público:

Es dificil hablar sobre esta pieza porque es como si se contara una historia policíaca sin desvelar el desenlace. El punto de partida de la acción es como un rompecabezas. Todo se mueve en el linde entre la fantasía y la realidad y si quitamos del público el placer de la solución, entonces reducimos el efecto del espectáculo. Los héroes del drama [...] son unos hombres que anhelan la felicidad $y$ que luchan por su propia verdad en una sociedad construida con mentiras y terror brutal. La obra refleja la profunda crisis actual de una parte de los intelectuales de la izquierda de la Europa occidental, el momento agitado de la redefinición de los objetivos $y$ de la búsqueda de los nuevos caminos. A pesar de las dudas e incertidumbres, la fe del dramaturgo es inquebrantable: en última instancia, no se puede comprar al hombre, que no puede renunciar a la libertad en ninguna circunstancia. El montaje del psicodrama de dos horas es una tarea dificil tanto para los actores como para el director, sin embargo, el placer de transmitir un mensaje moderno y el de la emoción de un juego sorprendente hacen agradable el trabajo en las tablas (“Az alapítvány”. Entrevista a László Babarczy, 1976). 
Tanto en la entrevista anterior como en la noticia del telediario se indica el género de la obra como psicodrama. András Hámori añade que el mismo autor utiliza la parábola como indicación genérica, y añade: "Parábola y mensaje. Mensaje a todos los que estén en peligro por las crueldades del poder [...]" (Hámori, 1976).

Las críticas del estreno fueron casi unánimemente positivas. "Es una pieza brillantemente construida. [...] Un psicodrama en el que cada escena provoca interés por la siguiente", escribe András Barta (1976). László Leskó habla de la obra y de la dirección en superlativo: "Una experiencia conmovedora, emocionante y catártica, después de la cual no se puede dormir en casa. Pero si se duerme, el primer pensamiento al día siguiente al despertarse es esta obra, esta experiencia. No se puede - no se quiere - librarse de este espectáculo que encadena un proceso de purgación" (1976). Y añade que no quiere escribir una crítica, más bien quiere hacer publicidad al drama y quiere tomar la mano de los lectores para conducirles a la obra, al teatro. "Este espectáculo tiene ánimo" — concluye"y gracias al más ilustre dramaturgo de los españoles, recibimos del palco teatral un juramento con la fuerza del 'no pasarán' [...]”' (Leskó, 1976). István Csík alaba también al dramaturgo:

La invención del autor realizada consecuentemente mantiene al espectador en incertidumbre. ¿Qué es lo que está contemplando? ¿La ilusión de la realidad o la realidad de las ilusiones? De escena a escena se disipa la tiniebla y proporcionadamente con eso aumenta la tensión y la fuerza sugestiva del mensaje escondido del autor (Csík, 1976).

Los otros críticos destacan también la maestría del método de sumergir al espectador en un ambiente en el que todo se ve desde el punto de vista de un personaje que sufre por un trastorno mental y psíquico.

Una voz menos positiva fue la crítica de Tamás Mészáros:

Confieso: más bien me enfadó y no me emocionó la primera parte del drama de Antonio Buero Vallejo. La tensión de estas escenas se alimenta de la circunstancia en la que los personajes saben algo que no quieren descubrir ni ante su compañero, ni ante el público. Así, 
los ataques de impaciencia que de vez en cuando cautivan a Tomás, no cuidan tampoco los nervios de los espectadores. [...] El drama influye solo en la mente y no en las emociones porque conocemos a los personajes solamente en su función y no su verdadero carácter. No se puede establecer contacto íntimo con ellos, no sabemos de ellos nada personal. Tampoco sabemos nada del régimen opresor, solo que encarcela a los rebeldes (Mészáros, 1976).

Tampoco Tamás Koltai estaba de acuerdo con la críticas elogiadoras, porque: "Después del espectáculo sentimos que algo faltaba [...]; en un entero acto [Buero Vallejo] engaña al público y no da posibilidad para que este llegue a la clarividencia gracias a la experiencia vivida en el proceso teatral. La experiencia intelectual deducida posteriormente no es el recurso más apropiado del teatro" ("Charla con Tamás Koltai en la radio", 1976). A pesar de estas reseñas poco positivas, András Barta llega a la conclusión de que "el espectáculo es uno de los eventos más importantes de la temporada en los teatros de la provincia y merece que lo vea un público más amplio, sea en forma de una retransmisión televisiva o como espectáculo invitado a un teatro de la capital" (Barta, 1976).

Las reseñas alaban el trabajo de los actores y sobre todo Ádám Rajhona (Tomás) y Róbert Koltai (Max) reciben un mayor reconocimiento. El primero hizo sentir bien la exaltación y, más tarde, la sensata determinación de un preso torturado e ilusionado. Según Mészáros, "Tomás es un hito importante en la carrera esperanzadora de Rajhona que logra formar el papel con simplicidad y sinceridad, evitando la trampa de la "sobreactuación"' (1976). Su temperamento fue compatible con la figura de Tomás, sin embargo, luchaba bastante en la construcción de los cambios internos de la figura. En el ropaje de Max, Koltai logró representar con un espléndido crescendo al carácter de un hombre de fiebre pasional (Barta, 1976). Merece atención también el juego de Katalin Kiss "que formó tan etéreamente a la amante nacida del deseo que sentimos casi desde el comienzo: tal mujer no puede existir" (Hámori, 1976).

El trabajo de la escenografía (Gyula Pauer) merece mención en las reseñas: "logra sentir el mundo de las ilusiones y las alucinaciones con una técnica brillante" ("P. I.", 1976); "el escenario recreó un ambiente espantoso" (Barta, 1976).

Leyendo las críticas, tenemos la sensación de que la dirección de 
László Babarczy fue exitosa: "un espectáculo sorprendentemente bien dirigido" ("P. I., 1976), "el ritmo de la dirección es perfecto" (Csík, 1976) y "la dirección construye el espectáculo minuciosamente y con autenticidad" (“Charla con Tamás Koltai en la radio", 1976). Babarczy logró crear en las tablas una tensión chispeante y pudo provocar interés tanto por la historia personal como por el contenido político, ideológico y moral (Barta, 1976).

El segundo estreno húngaro de La fundación se produjo tres años más tarde, el 30 de enero de 1979, en el Teatro Tamási Áron de Sepsiszentgyörgy, bajo la dirección de Attila Seprődi Kiss. Las críticas de este estreno fueron menos entusiastas que las del espectáculo de Kaposvár, de 1976. Vilmos Ágoston, por ejemplo, opina que cambiar el final de la obra no fue una buena decisión. Buero termina el drama con una acotación que alude a la repetición de la primera escena cuando Tomás imagina que está en una fundación: suena otra vez la música de Rossini, en la puerta aparece el director en un impecable traje y con un gesto cordial invita a los nuevos inquilinos de la elegante y moderna fundación. El crítico pregunta al director: ¿por qué tachó esta parte de la obra cuya función es dar un marco a la historia y sugerir que todo sigue igual? Para conocer la concepción de Seprődi Kiss cito la entrevista en la que participaron junto al director también los actores del espectáculo:

Seprödi Kiss.- Yo no quería poner en escena una cárcel abstracta, sino una más cercana a la idea que está en la cabeza de los espectadores

Ágoston.- Sí, pero, [sin el marco] la acción se simplifica, la obra pierde su sentido más amplio [...]

Seprödi Kiss.- Sí, es posible, sin embargo, pensamos que con los recursos simples que tenemos en este teatro, hay que tener en cuenta también a los espectadores...

Ágoston.- Eso sí. Depende mucho de la realización técnica, sin embargo, en este caso se trata de la interpretación...

Kuti ${ }^{30}$.- El autor imaginó su obra no tan simplemente sino con el uso de todos los recursos del teatro moderno [...]. Pero quién podía interpretar las escenas en las que hay que fumar, beber, telefonear, ver la tele sin cigarrillo, sin bebida, sin teléfono y televisor. Con

30 István Kuti interpretó el papel del director de la cárcel. 
muchos colores pero en el mismo ropaje gris de la cárcel. ¿Qué pensará el espectador? Apenas puede seguir qué sucede con la fundación. Y si la cárcel se transformara otra vez en una fundación... Ágoston.- Es deshonesto menospreciar tanto al espectador...

Seprödi Kiss.- Sí, pero tuvimos que adaptar la obra al público (Ágoston, 1979).

Es decir, la modificación del final de la obra se hizo para "considerar al público", pero, como constata el crítico, eso significa que el director desestima la capacidad de los espectadores. Además, con este cambio, un mensaje importante de Buero no llegó al público de Sepsiszentgyörgy. En la misma entrevista, Vilmos Ágoston critica que "la voz de los actores fuese muy alta". Seprődi explica eso por la mala acústica de la sala: "en la décima fila ya no se oiría nada" (Ágoston, 1979). Sin embargo, el crítico opina que "el espectáculo sería más dinámico si se transmitiera la tensión con un juego actoral más reprimido y no con el habla alta" (Ágoston, 1979).

La opinión de Lajos Kántor fue más positiva y comparaba la obra de Buero al drama Doce hombres en pugna. Opina que el mensaje de la pieza española es mucho más general y amplio, así, en este aspecto, incluso supera el famoso drama de Reginald Rose. Destaca que el trabajo del director no fue fácil, pero gracias a Barna Deák y Ria M. Deák, creadores de la escenografía, logró realizar el montaje tanto de la ilusión de la libertad como la de la cárcel, aprovechando la fuerza de los colores y las luces (Kántor, 1979). Según el mismo crítico, la figura de Tomás supone uno de los papeles más difíciles y más complejos de la literatura dramática moderna. László Csergöffy luchó con éxito con este carácter. Los otros actores tenían una tarea mucho más simple, aunque los personajes de Tulio (Árpád Visky) o de Asel (András Győry) no sean aburridos. La dirección organizó bien el juego actoral, concluye Kántor. Katalin Metz (1979) elogia a los actores, pero opina que la actuación de Katalin D. Vásárhelyi, en el papel de Berta, fue muy patética y sus escenas resultaban forzadamente sentimentales. También el rayo de luz que cubría a la mujer fue —opinabanal y no adecuado para escenificar los momentos psicológicamente más profundas (Metz, 1979).

La reseña (sin indicación del autor) de la revista Film Színház Muzsika destaca "el ritmo estrecho y la realización puntual" de la dirección y "la precisión psicológica de la formación de caracteres en cautiverio 
y del proceso que lleva gradualmente de un estado de ensoñación a la realidad del mundo cruel". Según el mismo artículo, "el espectáculo fue una de las mejores producciones de las últimas temporadas" ("Bemutató Sepsiszentgyörgyön”,1979).

\section{OTROS ESCRITOS HÚNGAROS SOBRE BUERO VALLEJO}

Aunque nuestro público pudo ver tres obras en cinco estrenos en el período comprendido entre 1963 y 1979, los lectores húngaros sabían muy poco sobre la obra de Buero Vallejo: en casos afortunados leyeron las críticas después de los estrenos, pero en ellas se ofrecían solo muy pocos detalles tanto de la biografía como de la obra dramática del autor. El historiador y crítico de teatro, Imre Gergely, quiso rellenar los huecos en la recepción con cuatro artículos importantes que se publicaron en la prensa húngara, de los que ya he mencionado uno que salió a la luz en 1989, como "prólogo que faltaba" del tomo Drámák de 1988.

Cronológicamente el primer artículo de Gergely fue publicado en 1979, justamente después del último estreno de La fundación. Este escrito es una entrevista que se produjo durante la visita del crítico a Madrid, donde se encontró personalmente con el dramaturgo español. El artículo - cuyo título es "La responsabilidad del escritor. Charla con Antonio Buero Vallejo"- empieza con la primera impresión de Gergely al ver al autor de El sueño de la razón: "un hombre de movimiento juvenil me espera a la puerta y su aspecto físico no revela el cansancio de una generación que sufrió mucho" (Gergely, 1979). Al mirar alrededor en la habitación, Buero Vallejo recuerda que el reportero húngaro descubrió un retrato que le parecía muy familiar:

El húngaro Imre Beer (conocido en España con el nombre del doctor Óscar Gorján) fue el jefe del servicio de salud de la $15^{a}$ división. [...] En aquel entonces pintaba y dibujaba más y no escribia tanto, por lo que también dibujé en 1938 el retrato de mi jefe y de mi mejor amigo de entonces. El doctor Gorján me encargó el servicio de prensa y propaganda del servicio de salud. Es decir, durante la Guerra Civil, mi mejor amigo y mi jefe era un húngaro (Gergely, 1979). 
Durante la entrevista hablaron también sobre los años pasados en la cárcel, su amistad con Miguel Hernández, tocaron el tema de la dictadura y cómo se podía existir y escribir durante la censura: "La censura tenía malas intenciones. Sin embargo, de mis 20 obras literarias, 18 fueron publicadas durante el franquismo, entre estas muchas piezas con voz crítica y luchadora" (Gergely, 1979). En cuanto a la actualidad, Buero cuenta al entrevistador húngaro algunos detalles sobre su obra recién nacida, Jueces en la noche $e^{31}$, en la que se ocupa de algunos imperativos morales de la joven democracia española. Buero Vallejo fue bien informado sobre los estrenos húngaros, pero parece que no sabía sobre el primer estreno de $E n$ la ardiente oscuridad (en 1963) porque menciona el espectáculo de 1972 como "mi primer estreno en Hungría" (Gergely, 1979).

El siguiente artículo de Gergely nos informa sobre otro viaje del crítico a España y ofrece un panorama teatral de España en el verano de 1985. Ese es precisamente el título del escrito publicado otra vez en la revista Film Színház Muzsika, en agosto de 1985. Es decir, en él no solo escribe sobre Buero Vallejo, sino que presenta a grandes rasgos la vida teatral española en la temporada en curso y en la anterior a su viaje, detallando también la política cultural del gobierno socialista de España. Este viaje, le brindó de nuevo la posibilidad de encontrarse personalmente con el dramaturgo de Guadalajara, que "estaba convaleciendo debido a una fractura de pierna" (Gergely, 1985a). Le habló sobre su obra Diálogo secreto, montada en agosto de 1984. "El estreno fue un evento importante y la obra fue el mayor éxito de la temporada, galardonada con el premio del público y de la crítica en 1984", según introduce Gergely la obra y luego la reseña brevemente. Comenta también que Buero Vallejo estaba de acuerdo con la política cultural del gobierno con cuyo apoyo se reestrenaron muchos dramas realistas contemporáneos y también de antaño. Gergely se encontró también con Javier Solana que le dijo que "en 1985, el gobierno apoya al teatro con 823 millones de pesetas, cuádruple de la subvención del año anterior, cuando la cinematografía fue más privilegiada”. Otro logro de la política cultural es "la renovación de 40 teatros de la provincia por seis mil millones. [...] Los teatros privados pueden obtener subvención estatal si ponen en escena a dos dramaturgos españoles por temporada, de

${ }^{31} \mathrm{Su}$ estreno se produjo un poco después de la entrevista de Gergely, el 2 de octubre de 1979, en el Teatro Lara de Madrid. 
los que uno tiene que ser autor vivo" (Gergely, 1985a) ${ }^{32}$.

Dos meses más tarde se data otro artículo de Imre Gergely (1985b), que es, sin duda alguna, el más importante y más extenso resumen en húngaro sobre el teatro de Buero Vallejo, publicado en la revista Színház, revista teatral más importante de Hungría. Por su fecha, podríamos decir que es bastante tardía, visto que los cinco estrenos de las tres obras buerianas fueron muy anteriores (en 1963, 1972, 1974, 1976 y 1979), sin embargo, merece nuestra atención ya que es una introducción muy buena a la vida y obra de Buero Vallejo: menciona momentos vitales del dramaturgo, enumera muchos títulos de sus obra y analiza en profundidad los tres periodos del desarrollo de la dramaturgia bueriana. Considerando que en los años ochenta, durante el régimen socialista, los húngaros no podían viajar tanto, el flujo de libros que llegaban desde el occidente no era tan masivo, rápido y libre como hoy, e internet tampoco existía, así que el artículo de Gergely en la prensa teatral húngara por fin hizo conocer a nuestros lectores al dramaturgo más importante de la posguerra española.

El último ensayo de Imre Gergely sobre Buero Vallejo se publicó en 1989, el ya mencionado artículo escrito con la intención de rellenar el hueco que dejó la falta de prólogo del tomo de sus dramas de 1988. Por eso, el título de este artículo fue "En busca de un epílogo olvidado". La única novedad que este escrito ofrece respecto a los anteriores es que en él Gergely menciona también el Premio Cervantes, concedido a Buero en 1986. Junto a la última columna del artículo se ve también una foto de Buero Vallejo delante de un cuadro de Joan Miró y el pie de foto: "El

\footnotetext{
${ }^{32}$ Resume también su experiencia personal en los teatros de Madrid, donde pudo ver La casa de Bernarda Alba, en el Teatro Español, con cuyo director, José Carlos Plaza, también se encontró. Otra noche, en la sala Goya del Círculo de Bellas Artes, vio El caballito del diablo, de Fermín Cabal (escribe erróneamente el apellido como "Cabalaz"), que "toca el tema de las drogas, el mayor problema de la juventud". Menciona también la renovación de Luces de Bohemia, en el María Guerrero, en la dirección "del joven y talentoso Lluis Pasqual" (Gergely, 1985a). Ofrece un panorama también sobre la movida vida teatral de Barcelona, que recibió un gran impulso con el congreso internacional de teatro, organizado entre los días 19 y 25 de mayo. Destaca la visita y la dirección en Barcelona de Ingmar Bergman (Shakespeare: El rey Lear). Con el motivo de la celebración del congreso se estrenaron ocho obras de las que Imre Gergely pudo ver dos: $L a$ pregunta perduta, del catalán Joan Brossa ("que no interesaba mucho al público") y Cyrano de Bergerac ("aplaudido con entusiasmo por los espectadores"). La primera dirigida por Hermann Bonin, la segunda, por Josep Maria Flotats y Maurizio Scaparro. La conclusión del crítico húngaro es que "el teatro experimental tiene mayor éxito en Madrid que en Barcelona" (Gergely, 1985a). Junto al artículo hay tres fotos: 1. El caballito del diablo; 2. Diálogo secreto; 3. La pregunta perduta.
} 
dramaturgo que colecciona pinturas de Miró” (Gergely, 1989).

\section{A MODO DE CONCLUSIÓN}

Para no romper la cronología de los cuatro escritos de Imre Gergely, hemos pasado por alto un artículo importante de Mária Bonifert, Merre tart a spanyol színház? (¿A dónde va el teatro español?), publicado en la revista Színház, en noviembre de 1981, y en la que la autora presenta detalladamente la situación del teatro español actual hasta 1980, mencionando muchos autores cuyos nombres eran hasta entonces desconocidos para el público húngaro. En este artículo de seis páginas hay también un párrafo que detalla la obra bueriana.

En las últimas décadas se publicaron en Hungría algunos escritos sobre Buero Vallejo que completan la recepción del dramaturgo fallecido en 2000. Entre estos merece ser mencionado el libro Színház és diktatúra a 20. században (Teatro y dictadura en el siglo XX) (Lengyel, 2011), que dedica un capítulo a la presentación del teatro español bajo Franco en el que podemos leer un apartado más largo sobre el teatro realista de Buero y un subcapítulo en el que el autor, Tamás Zoltán Kiss, resume el debate que surgió entre Buero Vallejo y Alfonso Sastre en torno al posibilismo (2011: 115-117).

Otro resumen, un artículo de Eszter Katona, Apuntes sobre la historia del teatro español en el siglo $X X$, se publicó últimamente en la revista Tiszatáj, en 2016, que también contiene unos párrafos dedicados al teatro bueriano (2016a: 59-60). En otro ensayo de la autora antes mencionada podemos leer una comparación entre El sueño de la razón, de Buero, y Cartas de amor a Stalin, de Juan Mayorga (Katona, 2016b).

Terminando, debemos reconocer que la recepción del teatro de Antonio Buero Vallejo en Hungría no es muy amplia y fuerte. A pesar del primer entusiasmo de nuestros traductores, de las once piezas traducidas al húngaro, como hemos visto, solo tres llegaron a las tablas en cinco estrenos $^{33}$ de los que, sin duda alguna, El sueño de la razón, montado en el Vígszínház, prestigioso teatro de Budapest, en 1974, despertó mayor interés tanto entre el público como entre la crítica. Lamentablemente,

33 La recepción polaca de Buero Vallejo es de semejante volumen: allí se estrenó igualmente $E l$ sueño de la razón, en 1976 y El concierto de San Ovidio, en 1990 (Aszyk, 2017). 
nuestro público no ha podido ver obra bueriana desde 1979, fecha del último estreno de La fundación. Quizás Imre Gergely dé con el motivo de la indiferencia de nuestros directores y teatros: "Buero Vallejo es un dramaturgo español hasta la médula. Le interesaba más representar el alma del hombre español que sufre entre circunstancias miserables, y no los problemas del hombre europeo de la segunda mitad del siglo XX" (Gergely, 1989). Gergely tiene razón en parte, pero tenemos que añadir que el valor parabólico sin didactismo de las obras de Buero Vallejo y el mensaje moral y profundamente humano de su teatro conquistaron a los espectadores por todo el mundo. Lo demuestra el éxito de sus estrenos desde la Unión Soviética de aquel entonces hasta los Estados Unidos.

Para terminar, puedo constatar lo mismo que Urszula Aszyk, gran investigadora de la recepción polaca del teatro español, que escribe a propósito de la acogida de Buero Vallejo en Polonia (2017: 268): debemos sentir que no se hayan trasplantado a la cultura húngara más obras del mayor dramaturgo de la llamada Generación Realista.

\section{REFERENCIAS BIBLIOGRÁFICAS}

[A.] (1963). "Valleyo [sic]: Égető sötétség”. Népmüvelés, junio, 34.

ÁGOSTON, V. (1979). “Alapítvány - vagy valami más?”. A hét, 16 de marzo.

ASZYK, U. (2017). "En torno a los estrenos de El sueño de la razón y El concierto de San Ovidio de Antonio Buero Vallejo en Polonia". En Fuera de contexto. Obras dramáticas, motivos y mitos españoles en el teatro polaco, 251-268. Varsovia: Museo de la Historia del Movimiento Popular Polaco / Instituto de Estudios Ibéricos e Iberoamericanos, Universidad de Varsovia.

BARTA, A. (1974). “Az értelem álmai. Spanyol dráma bemutatója a Vígszínházban”. Magyar Nemzet, 5 de junio.

(1976). "Az alapítvány. Antonio Buero drámája a kaposvári színházban". Magyar Nemzet, 27 de marzo.

BOGÁCSI, E. (1976). “Az égető sötétség. Vizsgaelőadás az Ódry Színpadon". Magyar Nemzet, 3 de marzo.

BONIFERT, M. (1981). "Merre tart a spanyol színház?”. Színház, noviembre, 29-34, http://old.szinhaz.net/pdf/1981_11.pdf 
[31/01/2019].

BUERO VALLEJO, A. (1961). Fedett kártyákkal. Budapest: Színháztudományi Intézet [manuscrito mecanografiado].

(1964). Ünnep. Budapest: Színháztudományi Intézet [manuscrito mecanografiado].

(1972). Alszik az értelem. Budapest: Színháztudományi Intézet [manuscrito mecanografiado].

(1974a). Az értelem álmai. Nagyvilág 4, 537-591.

(1974b). Az alapítvány. Budapest: Színháztudományi Intézet [manuscrito mecanografiado].

(1980). Bírák az éjszakában. Nagyvilág 11, 1633-1686.

(1982). Valmy doktor két története. Budapest: Színháztudományi Intézet [manuscrito mecanografiado].

(1988). Drámák. Budapest: Európa.

(s. a.). Az égető sötétség. Budapest: Színháztudományi

Intézet [manuscrito mecanografiado] (también en https://library.hungaricana.hu/hu/view/SZAK_SZIN_

Szindarabok_Q_00129/?pg=0\&layout $=l$ [20/01/2019]).

(s. a.). Kaland a szürkeségben. Budapest: Színháztudományi Intézet [manuscrito mecanografiado].

(s. a.). Egy lépcsőház története. Budapest: Színháztudományi Intézet [manuscrito mecanografiado] (también en https://library.hungaricana.hu/hu/view/SZAK_SZIN_ Szindarabok_Q_00256/?pg=0\&layout=l [20/01/2019]).

CSÍK, I. (1976). "Kaposvári Csiky Gergely Színház - Az alapítvány". Film Színház Muzsika, 13 de marzo.

F. F. (1963). "Égető sötétség. Bemutató az Egyetemi Színpadon". Esti Hirlap, 23 de abril.

FODOR, G. (1963). “Az égető sötétség. Az Universitas bemutatója”. Egyetemi Lapok, 11 de mayo.

GERGELY, I. (1979). “Az író felelőssége. Beszélgetés Antonio Buero Vallejóval”. Film Színház Muzsika, 8 de septiembre.

(1985a). “Spanyolországi Színházi körkép 1985 nyarán”. Film Színház Muzsika, 24 de agosto.

(1985b). “Antonio Buero Vallejo színháza”. Színház, octubre, 37-39. (1989). "Egy lehagyott utószó nyomában”. Film Színház Muzsika, 18 de febrero. 
HÁMORI, A. (1976). “Az alapítvány. Antonio Buero drámája a kaposvári Csiky Gergely Színházban”. Népszabadság, 26 de marzo.

HÁMOS, Gy. (1963). “Az égető sötétség. Spanyol drámabemutató az Egyetemi Színpadon". Élet és Irodalom, 4 de mayo.

HÁRSING, L. (s. a.). " $A z$ égető sötétség” [reseña del traductor sobre la obra, 4 hojas mecanografiadas]. Archivo del OSZMI.

(1963). “Az égető sötétség. Az Universitas-együttes április 27-i bemutatója". Egyetemi Lapok, 20 de abril.

ILLÉS, J. (1974). “Az értelem álmai”. Film Színház Muzsika, 18 de mayo. KÁNTOR, L. (1979). "Hat halálraítélt”. Utunk, 30 de marzo.

KATONA, E. (2016a). "Vázlata XX. századi spanyol színház történetéhez”. Tiszatáj, marzo, 53-86.

(2016b). "Müvészi szabadság - hatalmi önkény. Buero Vallejo Goya, Mayorga - Bulgakov". Tiszatáj, marzo, 87-98.

KISS, T. Z. (2011). “'Csend! Csend, ha mondom! Csend!' A spanyol színház a Franco-korszakban (1936-1975). En Színház és diktatúra a 20. században. Gy. Lengyel (ed.), 108-126. Budapest: Corvina / OSZMI.

KOLTAI, T. (1974a). “Az értelem álmai. Buero Vallejo színműve a Vígszínházban”. Népszabadság, 18 de mayo.

(1974b). "Színház vagy teártrum? Külföldi drámák az elmúlt évadban". Nagyvilág 8, 1250-1255.

LENGYEL, Gy. (2011). Színház és diktatúra a 20. században. Budapest: Corvina / OSZMI.

LESKÓ, L. (1976). “Az alapítvány”. Somogyi Néplap, 7 de marzo.

LÉTAY, V. (1974). “Goya éjszakája”. Élet és Irodalom, 1 de junio.

LÓPEZ SANCHO, L. (1970). "El sueño de la razón, de Buero Vallejo, en el Reina Victoria”. ABC Domingo, 8 de febrero, 63-64.

LÖKÖS Z. (1974). “ $A z$ értelem álmai. Vallejo-mü hazai bemutatója a Vígszínházban”. Pestmegyei Hírlap, 14 de mayo.

L-X. (1963). “Az égető sötétség. Antonio Guero [sic] Vallejo drámája az Egyetemi Színpadon”. Film Színház Muzsika, 14 de junio.

MAJOR, O. (1974). “A félelmek és a szorongások éjszakája”. Tükör, 28 de mayo.

MÉSZÁROS, T. (1976). “Az alapítvány. Bemutató Kaposvárott”. Magyar Hírlap, 1 de abril.

METZ, K. (1979). “A képzelt alapítvány”. Elöre, 28 de diciembre. 
N. J. (1976). “Vizsgaelőadás”. Film Színház Muzsika, 13 de marzo.

P. I. (1976). "Színházi levél - Az alapítvány". Zalai Hírlap, 18 de marzo.

PINTÉR, Gy. (1974). “A Goya-darabról, még próbán”. Néző, junio de 1974.

POSSONYI, L. (1974). “Az értelem álmai - Vígszínház”. Vigilia, agosto de 1974.

RAJK, A. (1974). “ $A z$ értelem álmai. Buero Vallejo drámája a Vígszínházban". Népszava, 10 de mayo.

RÉTHI, S. (1975). A magyar és nemzetközi drámairodalom alapértékei $a z$ ókortól napjainkig. Tomo I. Budapest: MSZI (también en https://library.hungaricana.hu/hu/view/SZAK_SZIN_Sk_1975_A_ dramairodalom_alapertekei_1/?pg $=1$ \&layout $=S[20 / 01 / 2019])$.

SERRANO, V. (2016), "Antonio Buero Vallejo, el hombre y su obra". Don Galán. Revista de investigación teatral 6, s. p. Disponible en línea: http://teatro.es/contenidos/donGalan/donGalanNum6/ imagenesCitadas.php? vol $=6 \& d o c=1$ 2 [31/01/2019].

SOMLYÓ, Gy. (1981). Picasso. Budapest: Helikon.

SZALONTAY, M. (1974). “Az értelem álmai. A Vígszínház bemutatója”. Esti Hirlap, 11 de mayo.

SZOMBATHELYI, E. (1974). “ $A z$ értelem álmai. Bemutató a Vígszínházban”. Magyar Hírlap, 18 de mayo.

SZ. SZÁNTÓ, J. (1966). Realizmus a színházban. Korszerü színház 90. Budapest: Színháztudományi Intézet (también en https:// library.hungaricana.hu/en/view/SZAK_SZIN_Ksz_O2_ Realizmus/?pg=2\&layout $=s[31 / 01 / 2019])$.

\section{ARTÍCULOS Y ENTREVISTAS SIN INDICACIÓN DE AUTORÍA}

(1969). "Director Calls Play 'Symbolic'”. UMSL Current, 9 de octubre, 10. Disponible en línea: http://www.umsl.edu/services/library/ university-archives/Student\%20Newspaper/Current,\%2019661969/1969/Current,\%200ctober\%209,1969.pdf [22/01/2019].

(1976). “Az alapítvány”, estreno en Kaposvár, noticia en el telediario, MTV, 5 de marzo, 19:30 horas.

(1976). “Az alapítvány”. Entrevista a László Babarczy, 6 de marzo.

(1976). "Égető sötétség”. Magyar Ifjúság, 26 de marzo.

(1976). "Charla con Tamás Koltai en la radio", 1 de abril. 
(1979). “Bemutató Sepsiszentgyörgyön”. Film Színház Muzsika, 21 de abril.

(2000). “Gyászhír”. Magyar Narancs, 11 de mayo.

Recibido el 11 de febrero de 2019.

Aceptado el 28 de febrero de 2019. 